\title{
Plasticidad onírica en los cómics autobiográficos de Rachel Deville
}

\author{
Dream plasticity in Rachel \\ Deville's autobiographical comics
}

\author{
Adela Cortijo Talavera
}

\author{
Universitat de València
}

\begin{abstract}
Adela Cortijo Talavera es profesora titular de la Universitat de València. Es especialista en narrativa francesa contemporánea y artes audiovisuales. Su línea de investigación se centra en el estudio del cómic y los principales ejes de sus análisis serían la historieta francófona, la relación intermediática con la literatura y la producción de autoras de cómic desde los años setenta hasta la actualidad. En 2007, organizó y dirigió un coloquio internacional sobre cómic de autoría femenina titulado: Literatura y cómic. Dibujos escritos-escritos dibujados: visiones femeninas. En marzo de 2008, organizó en la Universitat de València un seminario de cómic y literatura impartido por Thierry Groensteen. En diciembre de 2009, codirigió, junto a Álvaro Pons, el coloquio: Primeras jornadas de narrativa gráfica. En mayo de 2012, formó parte del Jurado de la 5. a edición de la Alhóndigakomik, junto a Antonio Altarriba, Yexus y Rafael Martínez. Entre sus artículos publicados, destacarían: «Autoras contemporáneas en la historieta española. Revisión de la etiqueta cómic femenino» en Arbor, 2011; «Sexualidad traumática en herederas del underground: Debbie Drechsler y Phoebe Gloeckner», en Tebeosfera, 2012 y «Mirada y representación del cuerpo femenino en el cómic francés: las autoras de Ab! Nana», en Diablotexto digital, 2016.
\end{abstract}

Fecha de recepción: 5 de marzo de 2018

Fecha de aceptación definitiva: 4 de mayo de 2018 


\title{
Resumen
}

Este artículo es una aproximación a las técnicas de inserción de los relatos de sueños en el cómic autobiográfico o «autobiocómic» y a las distintas posibilidades que ofrece el medio en la figuración simbólica del inconsciente. Para ello analizaremos la obra de Rachel Deville, Lobas (2007) y L'Heure du loup (2013), y reflexionaremos acerca de la combinación de motivos simbólicos, oníricos y surrealistas que consiguen exorcizar, mediante el dibujo, los fantasmas de esta autora. Ya sean de carácter teriomorfo o de juego con el parámetro espacial.

Palabras clave: Rachel Deville, cómic autobiográfico, relato onírico, animalidad, simbolismo.

\begin{abstract}
This article is an approach to the techniques of inserting dream stories in the autobiographical comic and the different possibilities offered by the medium in the symbolic figuration of the unconscious. For this we will analyze the work of Rachel Deville: Lobas (2007) and L'Heure du loup (2013), and we will reflect on the combination of symbolic and surrealist motifs that manage to exorcise, through drawing, the obsessions of this author. Whether they are teriomorphic or play with the spatial parameter.
\end{abstract}

Keywords: Rachel Deville, autobiographical comic, dream story, animality, symbolism.

\section{Cita bibliográfica}

Cortijo Talavera, A. «Plasticidad onírica en los cómics autobiográficos de Rachel Deville», en CuCo, Cuadernos de cómic, n. ${ }^{\circ} 10$ (2018), pp. 46-64. 


\section{Autobiografía y sueño}

El cómic, al igual que el cine y la literatura, entrelaza e impulsa desde sus orígenes los contactos fructuosos de la ficción, la ilusión y el imaginario con la materia del sueño. En 2014, Thierry Groensteen fue el comisario de la exposición antológica «Nocturnes: le rêve dans la bande dessinée», ${ }^{1}$ en la Cité Internationale de la Bande Dessinée et de l'Image de Angoulême, y en ella hubo una extensa muestra de distintos tipos de historieta onírica, en la que cabría señalar, en el apartado histórico, el germen de Little Nemo in Slumberland (1905) de Winsor McCay. Las otras cuatro secciones temáticas que se propusieron fueron: fronteras fluctuantes entre sueño y realidad, diarios de sueños, pesadillas y onirismo, y en ellas se exponían planchas originales de Guido Crepax, Moebius, Marc-Antoine Mathieu o David B. Y en lo que concierne a la participación de autoría femenina, el inventario señalaba los trabajos autobiográficos de la quebequense Julie Doucet y de las francesas Caroline Sury, Johanna Schipper y Rachel Deville.

Sin intentar elaborar en este estudio una lista exhaustiva de autores o marcar un recorrido evolutivo de historietas que se estructuran con líneas divisorias frágiles entre sueño y realidad, centraremos nuestra atención en los relatos de sueños como formas o procesos del género autobiográfico o de los «autobiocómics» — término propuesto por Ann Miller y Pratt Murray — ${ }^{2}$ de autoría femenina y analizaremos el caso concreto de Rachel Deville. En relación con la autorrepresentación o el grafismo egotista, vivencial, exorcizante, autorreflexivo, es evidente que la prolífica tendencia intimista en el cómic de los últimos decenios —en Francia desde los años ochenta - no es exclusiva de las autoras. En el ámbito francófono habría que citar sin duda los trabajos de David B., Frédéric Boilet, Jean-Christophe Menu, Lewis Trondheim o Fabrice Néaud... y la enumeración no acabaría ahí. Pero es cierto que existe una especie de asociación incontestable con la forma del autobiocómic y la producción de autoras únicas, guionistas y dibujantes. Las mujeres se adentran cada vez más también, y con éxito, en los géneros clásicos ficcionales, como puedan ser la fantasía, el western o la ciencia ficción. Ellas adoptan, trasladan, modifican o actualizan los dogmas y estereotipos de estos géneros tradicionales. En ese sentido, es significativo

${ }^{1}$ Groensteen, Th. Nocturnes. Le rêve dans la bande dessinée. Citadelles and Mazenod, 2013. Catálogo de la exposición.

2 Miller, A. y Murray, P. «Transgressive Bodies in the work of Julie Doucet, Fabrice Néaud and Jean-Christophe Menu: Towards a Theory of the "AutobioBD" ». Disponible en: http://epress.lib.uts.edu.au/research/ handle/10453/3320 
el hecho de que haya autoras que han entrado con fuerza en las factorías Marvel y DC y han conseguido actualizar con sus aportaciones los mitos, creando superheroínas que son no solo apreciadas por los lectores, sino también por las lectoras. Así, se demuestra que el filón de lo testimonial o del intimismo lírico no está reñido con lo maravilloso, lo fantástico, los argumentos de leyendas folclóricas o las pinceladas góticas. Pero se sigue ligando invariablemente la producción de autoras con el concepto de «cómic de autor» y con una propensión al monólogo interior. Un cierto arte literario y acercamiento a las formas del diario íntimo, de la confesión o del testimonio se asimila a priori con la historieta hecha por mujeres, especialmente en Francia a partir de los años noventa, en el momento de auge de la nouvelle bande dessinée, de la proliferación de editoriales independientes y del éxito del grupo del atelier Nawak de la Place des Vosges. Pero este no es solo un atributo insistente en las autoras contemporáneas, sino más bien una característica propia del artista del siglo pasado y del presente. Tras el éxito mundial de Persépolis (2000-2003, L'Association) de Marjane Satrapi, los cómics autobiográficos, los «autobiocómics» de autoría femenina se han propagado con distintas orientaciones o tentáculos, pero casi siempre con miradas incisivas y reflexiones retrospectivas a temas de la infancia, la familia, la sexualidad, la enfermedad y la muerte. Satrapi, Julie Doucet, Aurélia Aurita, Phoebe Gloeckner, Debbie Drechsler, Johanna Schipper, Alison Bechdel, Miriam Katin o Dominique Goblet son prueba de ello.

Los estudios sobre autobiografía en el cómic son numerosos y necesarios y versan sobre aspectos diversos en torno a las aportaciones formales del lenguaje del medio a estos proyectos de representación de una materia vital o vivencial, más o menos conflictiva, más o menos íntima. Y cuentan con consideraciones teóricas de gran envergadura respecto a la encarnación gráfica del autor, la autorrepresentación, el autografema, la autoapreciación o la autodepreciación, la labor con la temporalidad o la dialéctica entre sinceridad y mentira. Es posible explorar las posibilidades plásticas, estéticas y estilísticas que ofrece el cómic para tratar una introspección y una búsqueda identitaria alejándose o acercándose de forma voluntaria a un efecto de realidad y recreando en la plancha un espacio de exploración, de apertura y cierre y de concentración en sí mismo. En ese sentido, me parece significativo un artículo de Groensteen, «Autobiographie», ${ }^{3}$ publicado en agosto de 2014 en la revista en línea Neuvièmeart 2.0, en el que llevaba a cabo un recorrido amplio e histórico por el medio al adentrase en los territorios del yo. Y un artículo de Jan Baetens que publicó en la revista Belphégor, «Autobiographies et bandes dessinées», en el que afirmaba lo siguiente: «L'autobiographie en bande dessinée ne se produit pas dans un vide [...] Elle se situe dans une époque hantée par le culte de l'authenticité ou, plus exactement (et la nuance est capitale), de refus de l'inauthenticité». ${ }^{4}$ En ese rechazo de la falta de autenticidad o en ese combate por arañar los vestigios de la verdadera identidad, se puede establecer una

${ }^{3}$ Groensteen, Th. «Autobiographie», en Neuvièmeart 2.0, agosto de 2014. Disponible en http://neuviemeart.citebd.org/spip.php?article813

${ }^{4}$ Baetens, J. «Autobiographies et bandes dessinées: problèmes, enjeux, exemples», en Belphégor, vol. 04, n. ${ }^{\circ}$ 1, noviembre de 2004. Disponible en http://dalspace.library.dal.ca/bitstream/handle/10222/47689/04 01 Baeten autobd fr cont.pdf? sequence $=1$ 
evolución o distinguir distintas posibilidades de construcción identitaria en el cómic de autoría femenina contemporáneo. Y ahí es donde cabe la operación de incrustar en las viñetas mundos oníricos para crear no solo un efecto de ficción y evasión, sino un efecto de realidad o, mejor dicho, de autenticidad. El cómic autobiográfico se liga con facilidad a lo onírico y a los relatos de sueños gracias a la figuración del dibujo y a la transformación, que propicia el medio, de una idea abstracta en imagen. La búsqueda de lo «verdadero» o lo auténtico podría llevarse a cabo a partir de la representación de lo irracional, lo escondido o lo inconsciente. De manera que el terreno de lo simbólico, lo surrealista y lo onírico se potencia como manera de conocer las neurosis y de ahondar sin orden ni lógica en los sentidos y en la memoria afectiva proustiana con la que reconstruimos los recuerdos en un relato de vida. De ese modo, se ahonda en una nueva retórica visual fundada en metaforizar los pensamientos y las emociones. En el ámbito francófono, y en tanto que contemporáneos de Rachel Deville, cabría citar los trabajos de David B., en especial Le cheval blême (1992) publicado en la colección «Ciboulette» de L'Association, en el que ese caballo representaba la muerte de la que se pretende escapar a galope - la cabeza de caballo de The Nightmare de Füssli (1781) - y el diario de sueños de Les complots nocturnes (2005), diecinueve sueños registrados y dibujados entre 1979 y 1994, publicados en Futuropolis. En 2012, la editorial l'Apocalypse, de Jean-Christophe Menu, publica Le Rêveur captif de Barthélémy Schwartz. Una obra experimental en la que propone, con una técnica mixta que combina dibujo, fotografía y efectos gráficos varios, volver a sus pesadillas o rememorar sus sueños obsesivos de juventud. Ese mismo año, en 2012, se publica en l'Association La montagne de sucre de Sandrine Martin, en la que, con un dibujo a lápiz por página, nos cuenta una historia íntima de amor. El mismo año aparece L'cil de la nuit de Vincent Vanoli, quien, tras haber propuesto dos historietas autobiográficas anteriores, ofrece una cabalgata nocturna en cincuenta y cuatro planchas oníricas en las que surgen sus paisajes mentales gráficos. Y también es en 2012 cuando Éric Lambé publica su inquietante Le fils du roi en Frémok, relato de sueños que consta de noventa planchas dibujadas exclusivamente con un bolígrafo Bic azul o negro.

En ese contexto, un año después, en 2013, Rachel Deville publica L'heure du Loup en L'Apocalypse. Una recopilación de veintiún relatos cortos de sueños que realizó durante una estancia en la casa de los autores de Angoulême. Sueños dibujados, kafkianos, que la construyen junto a su imaginario y que tejen lazos con su primer autobiocómic: Lobas, publicado en castellano seis años antes, en 2007, en la colección Sin nosotras de la editorial Sins Entido. Una novela gráfica en la que expresaba su percepción animalizada de ella misma y de su hermana gemela en forma de lobas.

Deville nació en Firminy, cerca de Saint-Étienne, en 1972, quince minutos después que su hermana gemela, Anne. Desde niña se apasionó por el dibujo y compuso sus primeras historietas a los diez años. Realizó sus estudios, hasta 1996, en la facultad de Artes Plásticas y en 2000 se instaló durante nueve años en Barcelona. Desde 2005 se dedica por completo al cómic y la ilustración. Sus obras gráficas reflejan esa posibilidad de conjugar la búsqueda identitaria con el relato de sueños, creando motivos e indicios dibujados para comprender su universo personal e imaginario. A Rachel Deville le interesan los conflictos de la infancia, 
la relación con la madre, la dualidad, la sexualidad, el miedo atávico a la muerte..., pero de un modo muy personal, sin seguir necesariamente los clichés o estereotipos psicoanalíticos freudianos o lacanianos, y haciendo uso de una extraordinaria riqueza plástica en sus obras. Ella dibuja continentes manifiestos para dejar translucir contenidos latentes con mecanismos de figuración, desplazamiento y condensación. Y presenta un topo-análisis en el que los espacios interiores y las atmósferas irreales desvelan o clarifican parte de su intimidad. Rachel Deville cuestiona su construcción ontológica desde la infancia y adolescencia a través de la materialización visual de lo latente, de lo impalpable, de lo indecible, de lo inefable, de lo que, en el parámetro de lo real, sería también invisible. Deville trabaja con dibujos en blanco y negro, con los lápices HD de su infancia, sin usar la tinta china, y parece que suele pasar horas para dibujar sus viñetas de forma laboriosa y evocar un cierto retorno artesanal a los orígenes.

\section{Lobas. El doble teriomorfo}

Lobas ofrece una reflexión casi sartriana sobre la mirada del otro - «faut-il craindre le regard d'autrui?»— y ofrece rasgos post-surrealistas del imaginario y la estética de la autora, que toma conciencia del mundo que la rodea y de sus barreras con el uso, a veces, de la técnica de las correspondencias. En lo que respecta a su reflejo en el espejo, la autora-grafiadora-personaje atraviesa etapas diferentes, oscilantes, de atracción y repulsión hacia su hermana gemela Anne, durante la infancia y, especialmente, durante la desquiciante metamorfosis de la adolescencia, el periodo de afirmación y transformación por excelencia, tan apreciado en el cine de terror. Ellas se arrastran, se separan y se reúnen como a ambos lados de una cinta elástica, una contra la otra como polos opuestos, con la fuerza de un imán o un agujero negro, y así se tragan y se pierden la una en la otra. Rachel Deville manifiesta el pensamiento obstinado de que su hermana y ella hubieran podido ser la misma persona, indivisible, con un mismo cuerpo. Y esa idea martillea y repercute en su noción de dependencia y de deseo de independencia.

Ellas saben de su extrañeza a través de los ojos desorbitados e impúdicos de los «otros», de su perenne examen visual. Sorprendidas al ver su propia imagen repetida en las pupilas reflectantes del resto, se agreden, se hieren y se cubren los brazos de arañazos. Se sienten siamesas, ofrecidas en espectáculo como freaks frente a los otros niños de la escuela o del instituto. Niños dibujados como auténticos monstruos, cual Polifemo, cuya cabeza es solo un ojo gigante, como el de Magritte.

Se sienten escrutadas de manera agresiva, inquisitiva, y esa sensación produce en ella, en plural, en ellas, una noción negativa de sus cuerpos idénticos que se convierten en impersonales e intercambiables por el hecho de no ser únicos.

En su primer cómic autobiográfico, Lobas, Rachel Deville juega con la representación de la pesadilla. Retraza el crecimiento de su cuerpo escindido y la percepción de su ego dividido en dos, compartido con su hermana gemela. Iguales como dos gotas de agua. La gemelidad, 


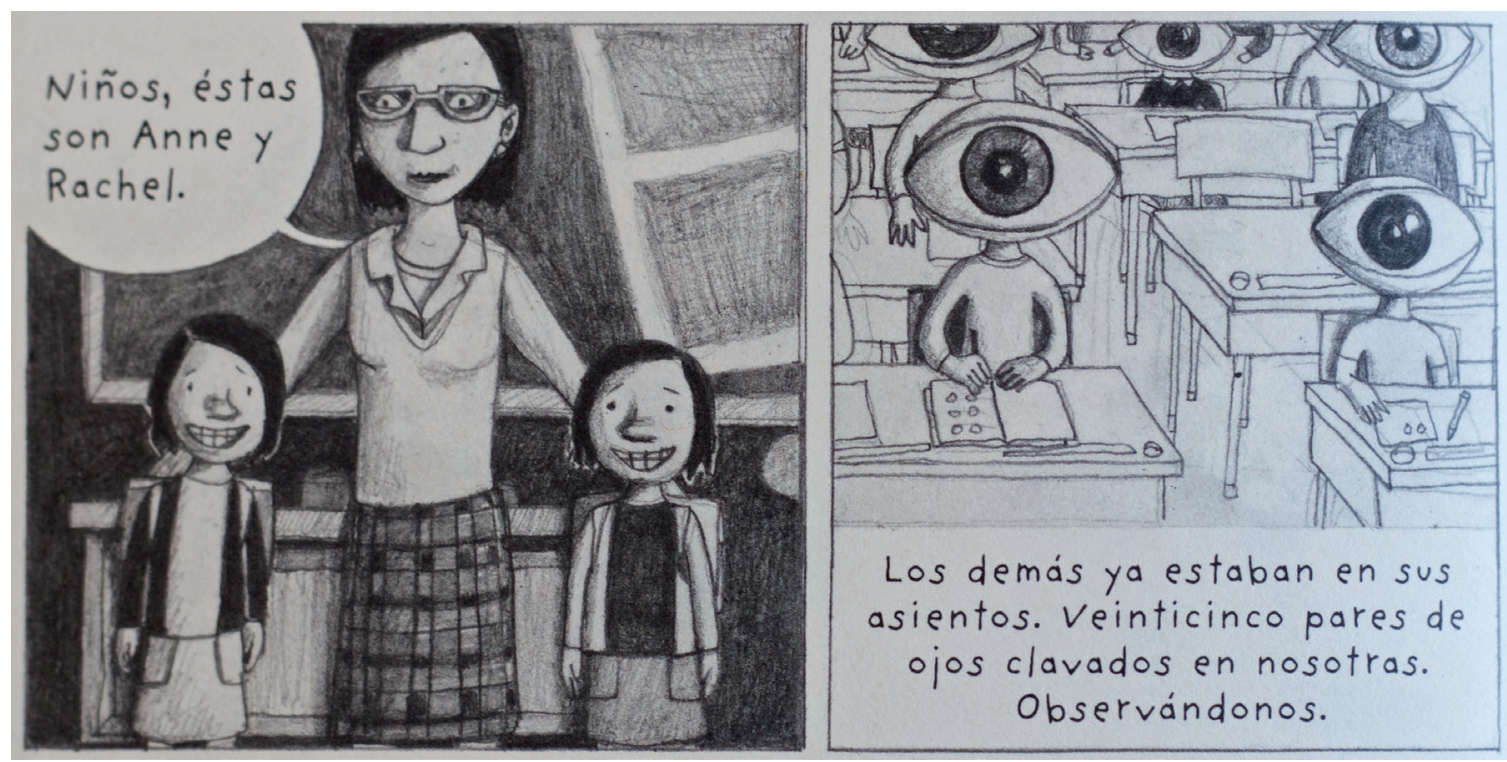

FIG.1.Deville, R. Lobas. Sins Entido, 2007,p. 44.

topos por excelencia de lo fantástico, se presenta como una figura de obsesión narcisista, un impulso de contemplar el propio cuerpo a través del otro, con una hermana que es un temido reflejo en el espejo. Y el dibujo del sujeto doble se propaga a través de los encuadres y montaje de viñetas regulares que hacen pensar en la repetición, así como en planchas simétricas que recrean imágenes duplicadas sorprendentes y, la mayor parte del tiempo, siniestras.

La reafirmación del yo se produce a partir de un odio y un combate de la una hacia la otra y, por metonimia, destruyen los objetos cotidianos que les rodean tratando de encontrar en vano algún elemento que sea de la propiedad individual de alguna de ellas.

«Todo lo que teníamos acababa deshilachado, doblado, roto, masticado. Objetos dispersos en un mundo disperso. [...] Deseábamos con ferocidad tener algo que fuera nuestro. [...] Y como no lo teníamos, encerrábamos el vacío en estuches imaginarios». ${ }^{5}$

Observables y observadas desde la cuna, se ahogan en un pasaje obligado de la barrera acuática de Narciso, que separa el mundo de arriba y de abajo. Pronto pequeños apéndices crecerán desde sus coxis de lobeznas porque la gemelidad se reifica y, sobre todo, se animaliza, relacionada con el satánico número par de la metamorfosis y de la licantropía, con la doble naturaleza humana, como les recuerda a las hermanas el minotauro en los meandros de su laberinto. En especial es durante la adolescencia cuando se vuelven más violentas y se convierten en jóvenes lobas esquivas, que muestran sus colmillos, esconden sus colas y maman de la loba capitolina, como metáfora hilada de aislamiento y salvajismo extremo entre ellas.

${ }^{5}$ Deville, R. Lobas. Madrid, Sins Entido, col. Sin nosotras, 2007. Traducción de Lorenzo F. Díaz, p. 54. 


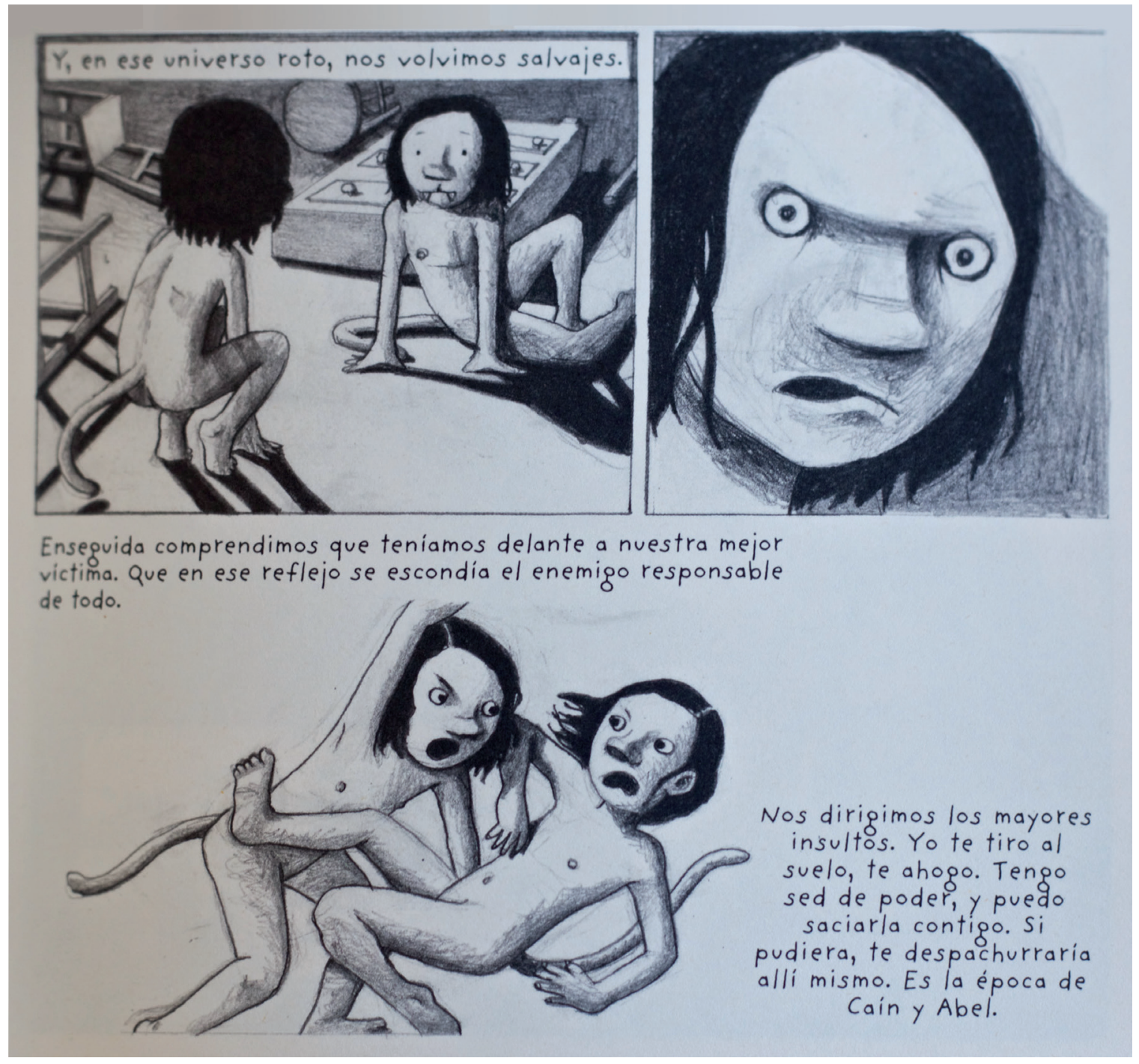

FIG. 2. Deville, R. Op. cit., p. 59.

Se trata de una imagen integrada, que hace de la metamorfosis un fenómeno extraordinario y al mismo tiempo ordinario. En este cómic con pinceladas surrealistas, el símbolo teriomorfo del lobo se impone, de este animal nocturno, gnóstico, de fauces negras que, como explica Gilbert Durand, ${ }^{6}$ devora como el tiempo y traga, como Saturno a sus hijos, para deshacerse de la amenaza del otro. Unido al deseo, a las pulsiones primarias, particularmente sexuales y que se repite en eco en L'Heure du loup, es un arquetipo arcaico. Los cambios asociados al crecimiento, al paso de la infancia a la adolescencia y luego a la edad adulta se hacen visibles gracias a esta animalización con rasgos oníricos ligada a la cuestión de la mirada. Una mirada que escruta, que salta y que ve doble, asociada a la repetición que destruye desde el principio toda posibilidad de unidad identitaria tranquilizadora. Las hermanas lobas que dibuja Rachel Deville se dan en espectáculo en el interior de una jaula o a través de una pared de cristal. Su aspecto de lobas

${ }^{6}$ Durand, G. Les Structures anthropologiques de l'imaginaire. Paris, Dunod, 1990 [1963], pp. 90-23. 
traduce su actitud defensiva y desafiante frente a la mirada que las petrifica. Anne y Rachel dejan entrever sus colas de lobas por encima de su ropa. Rachel Deville se presenta, a ella y a su hermana, como animales al acecho, animales que evocan los peligros de los cuentos folclóricos, de las leyendas de hombres lobos. Ella utiliza en las viñetas de Lobas toda una serie de motivos primitivos, antropológicos y de figuras prestadas del surrealismo, relacionadas con el doble, lo híbrido, lo monstruoso y el contraste constante entre lo infinitamente grande y lo infinitamente pequeño en espacios sin referentes con el fin de rescatar los momentos de su infancia.

Deville elabora también en su autobiocómic la variante de los relatos de filiación, de los que habla Dominique Viart, ${ }^{7}$ que muestran no solo una etapa de vida, sino que se encuentran en

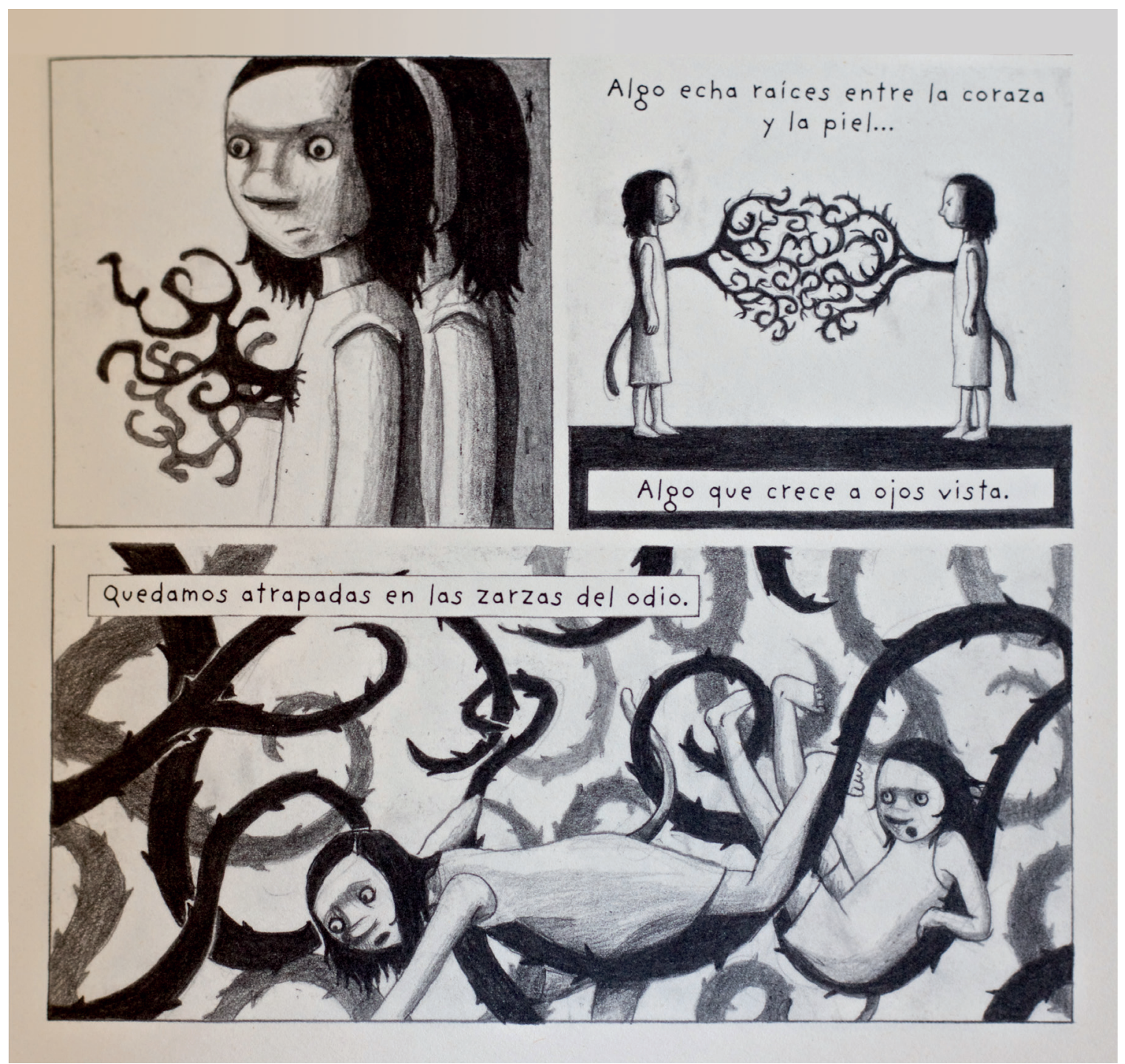

FIG. 3. Deville, R. Op. cit., p. 73.

VIART, D. «Filiations littéraires», en BAEtens, J. y Viart, D. Ecritures contemporaines. vol. 2. États du roman contemporain. Caen, Lettres Modernes Minard, 2000. 
la base de la materia psíquica y de una escritura gráfica de sí misma descentrada. Y, en eso, parece que las autoras son más proclives a señalar la perversidad de relaciones familiares hipócritas y ponen en evidencia violencias escondidas y una agresividad latente y subterránea de la que no se habla pero que se evidencia.

La autora señala, desde su primera novela gráfica, la dificultad de aprehenderse fuera de su hermana y del círculo de su familia, sobre todo de la figura de la madre. Las gemelas han sido amamantadas a los pechos de la loba latina, de una madre cruel, resentida y colérica tras el divorcio con el padre ausente. Las relaciones tortuosas con la madre se encarnan en largas ramas negras de espino que rodean y atan a las hermanas en sus zarzas.

En Lobas se modela una figura materna inquietante, como sucede también en el caso de Chantal Montellier con una madre medusa en Un deuil blanc (1987), o la madre castradora de Nathalie Ferlut en Lettres d'Agathe (2008, Delcourt), que prefiere a sus hijos varones y desprecia a su hija, o la madre ausente de Dominique Goblet en Faire semblant c'est mentir (2007, L'Association). Son madres posesivas que alienan y que en lugar de proteger surgen amenazadoras. Esta madre con cuatro brazos, que pretende hacerlo todo, está presente desde el principio, desde el parto, y es un ser ambivalente — «la madre es todopoderosa, a la vez que carente de fuerzas»,$-{ }^{8}$ mientras que el padre se muestra indiferente a las tareas de la procreación y la educación. La madre encuentra también su doble, su calco, su sombra, en la madre pequeña, en la hermana mayor de las gemelas. Cuando la madre se pone enferma, esta enfermedad se representará de nuevo metafóricamente como una rama negra de espino que sale de su interior por su boca y la atraviesa. Ella será la primera en ponerlas en contacto con la muerte.

La metáfora visual de la enfermedad es una cuestión recurrente en este tipo de relatos gráficos autobiográficos, en los que el dibujo consigue plasmar con figuras retóricas o símiles visuales un dolor que de otro modo sería difícil de expresar. En ese sentido, además de Rachel Deville cabría citar el caso de los seis volúmenes de L'Ascension du Haut-Mal (19962007) de David B., donde el autor-grafiador-personaje marca su vida, desde la infancia, con las crisis de epilepsia de su hermano, un «Haut-mal» que adquiere rostros de monstruos. $\mathrm{O}$ un virus con forma de rinoceronte en Pilules bleues (2001) de Frederik Peeters. O La tendresse des pierres (2013) de Marion Fayolle, que aborda con pudor el cáncer y la muerte de su padre.

En Lobas, la separación de los padres desvelará la locura y extrañeza de una madre que corre en sujetador y bragas con la boca llena de dentífrico como un animal con rabia. Dentro de una jaula de pájaros, las hermanas confirman su percepción de la realidad. Y al producirse la ruptura familiar, se creará un sector masculino y otro femenino como si hubiera que aprender lecciones de feminidad. Rachel y Anne se quedarán junto a una madre encolerizada, bruja o mujer gigante, que inunda la casa con sus gritos e invade el espacio, como un ogro, con su pie o su cabeza desproporcionadas, provocando el terror de sus hijas. La madre les obligará a

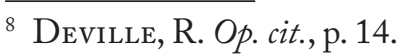


ocuparse de las tareas de la casa y les impondrá un modelo de mujer obediente y sumisa. La casa, al igual que la escuela, es un territorio hostil que hará crecer el odio en ellas como las ramas de espino. Ese sentimiento de ira les unirá contra la madre, y se volverán insensibles a su dolor, impasibles sumergidas en una cocina inundada por las lágrimas de la madre.

La problemática de la filiación se extiende en Lobas hacia los «otros», como llaman las hermanas al resto de la humanidad que no participa en su universo dual. Ellas trepan a las ramas de un árbol, símbolo de crecimiento, y miran desde lo alto a otros seres, duplicados simbólicamente por sus sombras y se sienten las reinas de las fisuras, la de su cigoto resquebrajado. La incomunicación es evidente ya que las hermanas gemelas crean un universo particular que les es propio, en su guarida usan un lenguaje que solo ellas pueden comprender y se encaraman sobre árboles imaginarios desde los que observan a los otros como si fueran insectos minúsculos que no las pueden ver. O bien se introducen en nichos redondos, cerrados, ováricos, a los que acceden gracias a puertas carrollianas que dibujan a medida de su necesidad en las paredes, al tratar de huir de los gritos e insultos que intercambian sus padres en guerra. Pero estos receptáculos circulares, seguros, con muros reflectantes, se harán cada vez más pequeños hasta que sea imposible refugiarse en ellos.

Ese lugar extraño, angustioso, de pasillos interminables, de puertas sin llaves, de sombras monstruosas, como el de Alicia en el país de las maravillas, se reproducirá en varias ocasiones en las pesadillas de L'Heure du loup. Las lobas saldrán del encierro cuando se produzca la separación, cuando abandonen el hogar. Una irá hacia el norte y la otra hacia el sur. Rachel llegará a Barcelona y no dejará de escrutar su imagen en los espejos de los escaparates. Redescubrirá su cuerpo de nuevo, en las miradas de aquellos que no la conocen por partida doble.

\section{L'Heure du Loup. Cartografía de sueños oscuros}

En su segundo trabajo, L'Heure du loup (2013), Rachel Deville transcribe o transfiere sus sueños al cómic en una obra fragmentaria en la que sus microrrelatos se revelan como un ejercicio más nebuloso que el proyecto autobiográfico en sí. Jacques Samson expone en «Le rêve: un embrayeur pictural» el poder y la capacidad del dibujo para esta tarea de aclarar la negrura del pozo interior que se oscurece en el tiempo. Negrura que Deville potencia con los trazos grasos de sus lápices carbonosos.

Qui sait d'ailleurs si le dessin (ou l'univers pictural en général), surtout quand il fraye en toute liberté avec les convulsions du fantasme n'entretient pas un lien tout spécial avec le monde des fixations et des obsessions, justement parce qu'il fixe encore plus intensément la mémoire de l'émotion que les mots écrits ? [...] une poésie du désert et de la nuit, grouillante et bruissante de tout ce qui habite le monde de l'éblouissement comme celui des ombres. ${ }^{9}$

9 Samson, J. «Le rêve: un embrayeur pictural», en Neuvièmeart 2.0, n. ${ }^{\circ} 11$, octubre de 2004. pp. 78-81. Disponible en http://neuviemeart.citebd.org/spip.php?article228 
El diseño de la portada de L'beure du loup es significativo: en un fondo azul oscuro, ella nada o vuela en el límite de la superficie del agua, donde los peces vuelan y los pájaros nadan y sugiere, desde el inicio, una ventana a un universo interior, inconsciente y sombrío. Deville recurre a su autografema y desnuda su psique gracias a los dibujos de sus obsesiones y sus pesadillas. L'heure du loup sigue de cerca el simbolismo animal teriomorfo y hace hincapié en la presencia de lo salvaje en un cronotopos tétrico e inquietante. Las masas negras de los lápices de grafito se imponen en los títulos de los sueños y en los decorados y los fondos de las viñetas no delimitadas, flotantes como nubes negras de tormenta sobre las planchas. El unheimlich freudiano se convierte en una puerta abierta a la creación, como las sesiones de los rêves éveillés de Desnos, Breton, Éluard o René Crevel. Casi como las prácticas de dibujos espiritistas o las psicografías. En ese sentido, es interesante señalar que Rachel Deville desarrolla un proyecto de psicorretratos.

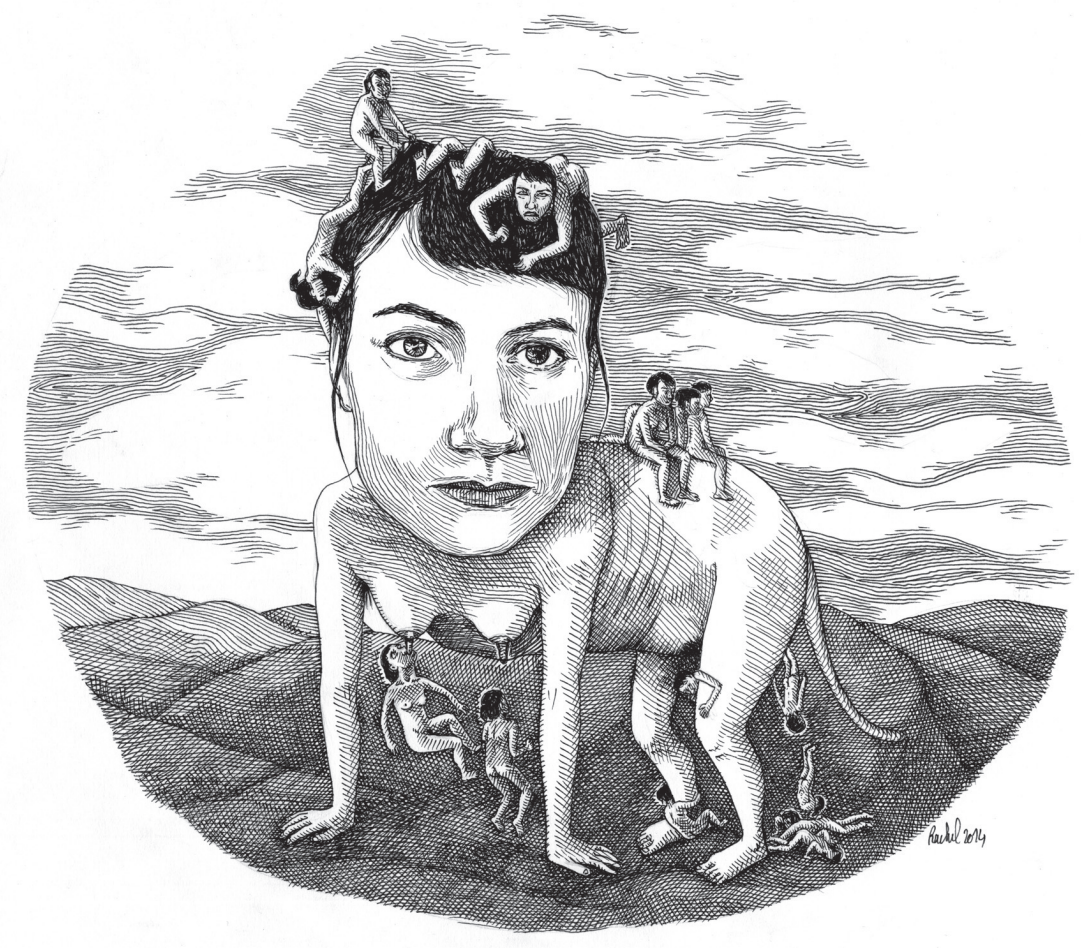

FIG. 4. Deville, R. Psicorretrato n. ${ }^{\circ} 14$. Junio de 2014. En su web: racheldeville.wordpress.com.

Los dibujos de L'Heure du Loup servirían para acercarse al estado hipnótico - como Les Champs magnétiques (1919) de Breton y Soupault - para liberar la expresión instintiva a través del dibujo, como pueda ser el dibujo mediúmnico o aquel propiciado por las técnicas surrealistas del collage, el frottage, el grattage, el fumage, la calcomanía o el juego del cadavre exquis. «La pensée libérée vogue à son gré», afirma la autora en el documental Rachel Deville, la rềveuse éveillée. ${ }^{10}$

${ }^{10}$ Video documental con entrevista a la autora sobre L'Heure du Loup, con motivo de la exposición Nocturnes: le rêve dans la bande dessinée. Disponible en https://www.youtube.com/watch?v=a3UgfNHPNKU 
En sus sueños, a menudo su personaje anda descalza como los muertos y se pierde en una incesante deambulación. Los lugares que aparecen sin cesar son la casa familiar, la facultad de Artes Plásticas... espacios referenciales que se reconocen, pero se desplazan gradualmente de la realidad. Las estructuras espaciales narrativas que se privilegian son el laberinto y la espiral, paisajes mentales que reafirman y exteriorizan una pérdida existencial. La repetición obsesiva de pasillos, de puertas, de sombras en los dédalos de casas en ruinas, fracturadas, de fábricas lúgubres, de hospitales, de túneles de metro, sirven para evocar siempre el tema del doble. Existe, además, en las viñetas de este cómic, una acumulación de espacios carcelarios y de subterráneos obscuros que se cierran y se empequeñecen hasta reducirse a la nada. En los sueños «L'escalier», «Mourir ou ne pas mourir», «La jeune fille et le cercueil», «La tour» o «La caverne de Javier», Rachel Deville despliega georretratos íntimos. Se prolonga cual espectro en el espacio que la contiene, y evoca así la falta de orientación, la enfermedad y la muerte. La «Chambre carrée et froide d'hôpital» exhibe un espacio de morbidez, y esos pasillos de hospital desiertos recuerdan los de los mangas de terror, con un aire de manicomio sucio, mugriento y destartalado. Así como los edificios impersonales de apartamentos hacen pensar en una modernidad en agonía, contrastan con los lugares góticos más tópicos del género fantástico: subterráneos húmedos, castillos tenebrosos, antiguas y grandiosas bibliotecas polvorientas o capillas de suelo ajedrezado. Sitios en los que los interiores son más preponderantes que los exteriores y los encuadres son a menudo cenitales, con el fin de aplastar a las figuras y empatizar con una mirada dominante, con ángulos oblicuos, cinéticos, nerviosos.

El temor irracional a la muerte está presente y, como sucede en la obra onírica de David B., se materializa en esta recopilación de relatos gráficos de sueños por medio de motivos espaciales simbólicos y arquetípicos, como el uso de escaleras poco fiables, poco sólidas, que no llevan a ninguna parte y juegan con una falacia de verticalidad.

En «L'escalier», el personaje femenino se ve obligado a dormir en una escalera inmensa, encima de unos escalones inconfortables con aristas hirientes. Desde un punto de vista alegórico, los escalones permiten cambiar de nivel de consciencia y la escalera se impone como el emblema de la progresión, de la ascensión y la transfiguración. Pero reviste también el aspecto negativo del descenso, de la caída, de la vuelta a la materialidad y al mundo subterráneo, como bien explica Bachelard en L'air et les songes. ${ }^{11}$ Participa en la metáfora axiomática de la verticalidad, y también de la espiral.

En L'beure du loup aparecen a menudo dibujadas escaleras de madera, frágiles, inconsistentes, que se superponen como en un puzzle sin principio ni fin, sin orden ni concierto, como sucede en los dibujos y litografías de Escher, en los que las perspectivas pervertidas son imposibles y las ilusiones ópticas distorsionadas, los cóncavos y convexos corresponden a una mirada alucinada. Rachel Deville representa, gracias a esta construcción laberíntica sin lógica del espacio, los ciclos, la dualidad y la persecución de un equilibrio perdido, el del blanco y negro, la simetría y el contraste del infinito y sus límites, el de los objetos y su contrapartida.

${ }_{11}$ Bachelard, G. L'air et les songes. Paris, Livre de poche, 2001 [1943]. 


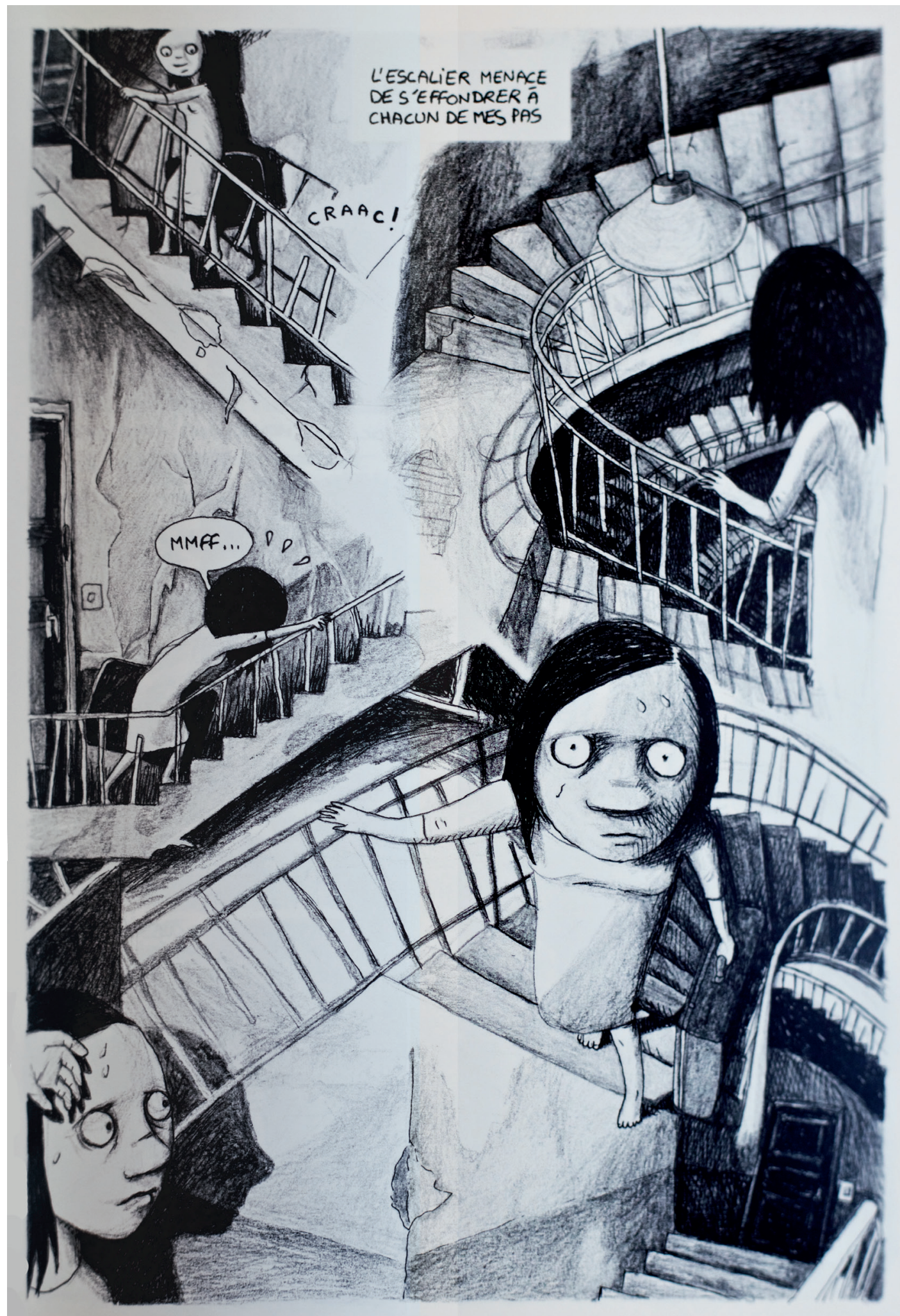

FIG. 5. Deville, R. L’heure du loup, L'Apocalypse, 2013. 
La verticalidad es cuestionada por la figura helicoidal de las escaleras de caracol que se entrecruzan. El nido no existe, se ha quemado, «Maison brûle», o bien se relaciona con lo polvoriento. En «La tour», el título, arcano XVI, hace referencia al edificio en el que vivía la familia y que aparece en Lobas; esa colmena vertical se muestra de forma negativa. El caos reina en el redil, con habitaciones que no son hospitalarias. Semejantes a los decorados de las películas de terror, dibujadas a veces en picado y con objetos rotos, cochambrosos, que parecen incluso malolientes, en cuartos de baño sucios con grifos de los que gotea el agua.

En «La caverne de Javier», el apartamento se describe así: «on dirait un immense labyrinthe constitué de fines cloisons et délimitant de minuscules pièces. [...] une multitude de minuscules ampoules clignotent au plafond comme autant de petites étoiles de pacotille». ${ }^{12}$ La deambulación siguiendo mapas erróneos o no legibles, las retrospecciones constantes, espaciales y temporales, el retorno a la infancia en «La belette» o a la adolescencia en la «La caverne de Javier», y la carrera sin sentido, la cabalgata nocturna de pesadilla cuando cree llegar tarde al trabajo, a su cita con el médico o a una lectura pública... En definitiva, en esta obra se suceden desplazamientos que no sirven para nada y que provocan la desesperación y la confrontación con situaciones absurdas y con exigencias de un orden hipotético e irreal. Otra figuración de este orden impuesto e inútil es la presencia reiterativa de una mujer con gafas, moño y labios crispados. Una especie de institutriz insensible y distante que impone clasificaciones ridículas y reglas de una burocracia de resonancias kafkianas en lugares grises y gélidos. Por ejemplo, en «Le maître du jeu» o en «Mourir ou ne pas mourir». La confrontación con los otros, con la multitud que aísla, es aún más es recurrente en L'Heure du loup que en Lobas. Las cabezas convertidas en glóbulos oculares gigantes se repiten en «La caverne de Javier», relato de sueño en el que la mirada y el deseo se amplifican en el encuentro en el taller de pintura y en el voyerismo de la caverna. Pero es sin duda «La lectrice» el relato en el que el personaje femenino y narradora de la historia se siente más agredida al ofrecerse en espectáculo, cuando debe hacer una lectura pública de un libro sobre el Bauhaus casi desnuda y con la voz rota.

Una impotencia que se repite en las idas y venidas sin finalidad alguna. Su estado psíquico se colige del parámetro espacial onírico, ya que las figuras que la rodean se presentan a menudo como marionetas o maniquíes sin rostro ni identidad, como las figuras de De Chirico, con agujeros en el rostro y con lenguajes incomprensibles. Su hermana gemela, Anne, a veces se une a ella para protegerla, como en «Mourir ou ne pas mourir», pero también es utilizada como un polo opuesto. Si Rachel se viste de blanco en el primer sueño, su hermana Anne lo hará de negro. En un callejón encuentra dos perros salvajes, en alusión a la hermana loba, o bien se repite en las dos mujeres gigantes que encuentra en la playa en «La lectrice», dos amazonas picassianas, grecolatinas, que se multiplican en eco en las mujeres estatuas de la biblioteca, motivo mitológico de reificación y repetición. $\mathrm{O}$ en «La fille sans visage», la sombra de la hermana, de los Dioscuros, se adivina en la competición con otra chica actriz, ellas corren a través de subterráneos mortuorios con bandejas llenas de vasos de cristal y cuando se despierta, el personaje llama a su hermana, pero a su lado solo hay una muñeca, parecida a ella, aunque sin rostro y sin respuesta posible a la pregunta de quién es.

12 Deville, R. L’heure du loup. Paris, L’Apocalypse, 2013. Sin número de página. 


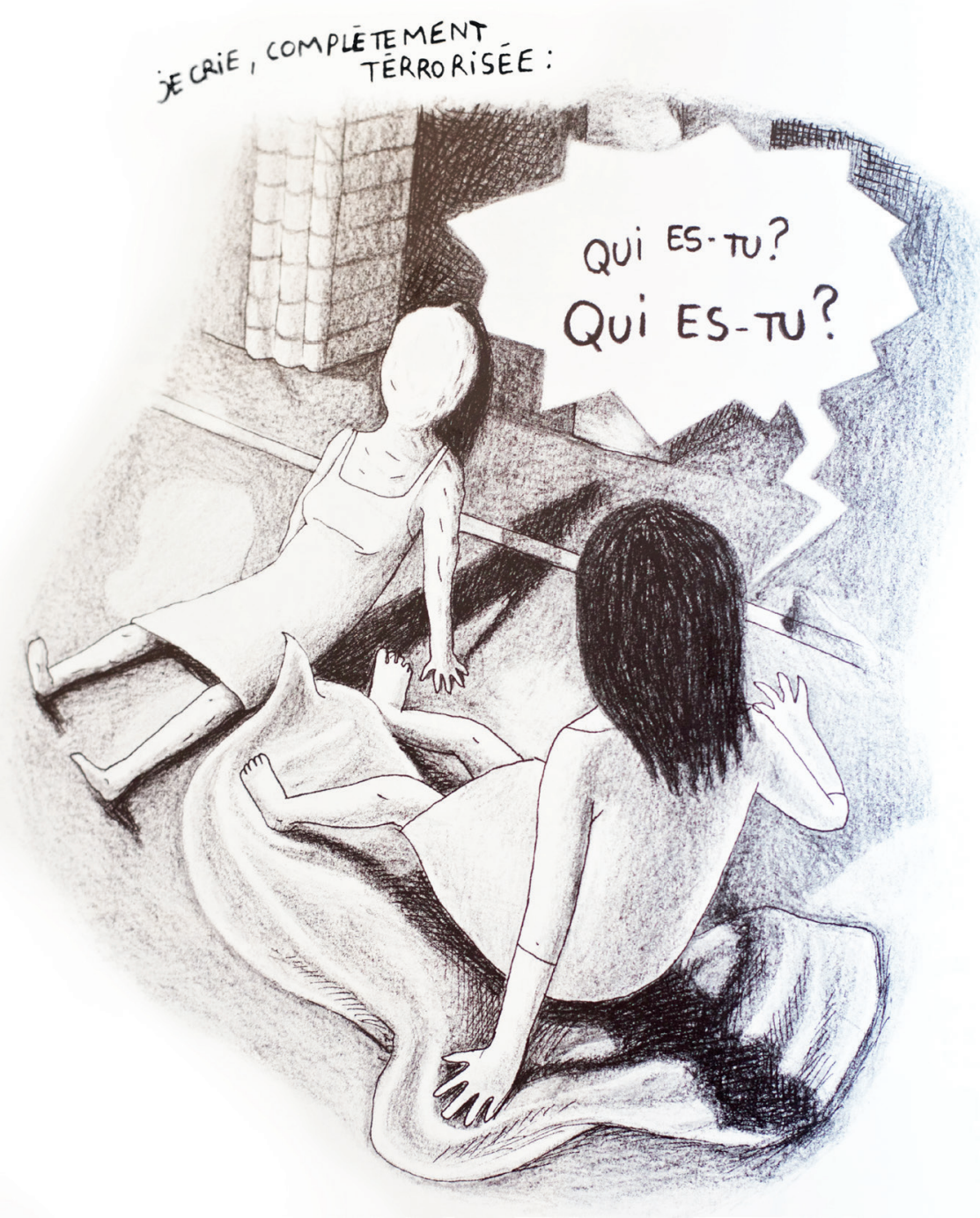

FIG. 6. Deville, R. L'heure... Op. cit.

Los relatos de sueños gráficos de Rachel Deville son historias de búsqueda, de encuentros y de pérdidas, en los que la descomposición o deconstrucción del espacio se traduce también en la desmembración de la figura, del cuerpo, con cabezas sin rostro y manos mutiladas. La mano cortada traduce su imposibilidad de dibujar, desmembramiento significativo como la mano de Un chien andalou de Buñuel, o como la oreja de Blue Velvet de David Lynch. La mano escindida es la protagonista de dos sueños «La belette», en el que este pequeño mamífero agresivo le muerde y paraliza su mano con veneno, $\mathrm{y}$ «La main coupée», en el que unos buenos amigos le cortan la mano y después se la cosen. La angustia de la parálisis de una mano que no sirve para nada refleja, especialmente para una dibujante, la imposibilidad de actuar, la dependencia, y la inacción, así como las esperas insólitas, las carreras sin sentido o la imposibilidad de comunicación. 
Le lector voyeur sigue a la soñadora en sus recorridos tortuosos por las tripas metálicas, pero también a través de las nubes cuando se permite volar ejerciendo una libertad extrema. Al final del último sueño llega al lago negro: «Le lac noir». Un relato de título evocador, con resonancias lamartinianas y de muerte romántica. El cronotopos de esta recopilación de relatos de sueños acaba en lo informe, con un retorno a la materia acuática y a la oposición de la superficie y la profundidad. Junto a los castillos encantados y los fantasmas de Escocia, con un interior gótico, de sombras expresionistas, ella debe atravesar el lago de aguas negras y frías, la nueva Estigia, con materias viscosas como en los cuentos de Lovecraft. Se sumerge en el dark water, en la negrura nocturna del agua, del sueño y de la boca del lobo.

\section{Conclusiones}

Hemos observado, en el topo-análisis de este corpus, los mecanismos y técnicas empleados por esta autora de cómics para transferir en sus relatos oníricos retazos de sus obsesiones y de su cuestionamiento identitario que parte de una escisión. Entre otros, el uso constante de la metamorfosis en animal y de un parámetro espacial angustioso, marcado por la estructura simbólica del laberinto, la ambivalencia de la vertical y la espiral. Rachel Deville dilata en los dibujos, casi terapéuticos, de Lobas un yo dividido entre ella y su hermana gemela y transmite la oscuridad escondida en un relato de filiación turbador.

Hemos reflexionado, gracias al análisis particular de esta autora, acerca de la particularidad del medio, en cuanto a su carácter visual y secuencial, para plasmar el devenir del yo y ciertos estados emocionales conflictivos que pueden expresarse con un lenguaje no verbal, en ocasiones con poesía o tragedia visual. En ese sentido, Rachel Deville muestra concomitancias con otras autoras del cómic francobelga actual, como Dominique Goblet (Les hommes-loup, 2010), Valentine Gallardo y Mathilde Von Gheluwe (Pendant que le loup n’y est pas, 2016), por citar algunos ejemplos que, de algún modo, siguen de cerca las reflexiones de Nathalie Sarraute acerca de la sous-conversation y de la importancia de la materialidad física del lenguaje. Hemos tratado de centrarnos en diversos puntos o apuntes epistemológicos del yo, como podría ser la representación del propio cuerpo como objeto visible que oscila entre lo íntimo y lo externo. Teniendo en cuenta las innovaciones y experimentaciones gráficas de Rachel Deville, esta autora plantea en sus autobiocómics oníricos cuestiones opuestas, como la normalidad y la alienación, la cotidianidad y lo sublime, los procesos de transformación física y psíquica o la confrontación con los otros. Expresa la construcción de su identidad, de sus fantasmas y su dualidad mediante la figuración simbólica de su subconsciente. Al tiempo que propone una reflexión acerca del contacto complejo entre realidad vital y ficción, haciendo hincapié en la complejidad de perfilar imágenes mentales parciales y vagas, ya sean sueños o recuerdos gracias a la precisión y la naturaleza del dibujo. Y se hace evidente, en la obra de Rachel Deville, que es el lenguaje mismo del cómic, su soporte, sus códigos y sus leyes, los que suscitan y determinan las peripecias de sus sueños. 


\section{Bibliografía}

Bachelard, G. L'air et les songes. Paris, Livre de poche, 2001 [1943].

—La poétique de l'espace. Paris, PUF, col. «Quadrige», 2001 [1957].

Batetens, J. «Autobiographies et bandes dessinées: problèmes, enjeux, exemples», en Belphégor, vol. 04, n. ${ }^{\circ}$ 1, noviembre de 2004. Disponible en http://dalspace.library.dal.ca/ bitstream/handle/10222/47689/04 01 Baeten autobd fr cont.pdf? sequence=1

David B. Le cheval blême. Paris, L'Association, col. Ciboulette, 1992.

- L'Ascension du Haut-Mal. Paris, L'Association, 6 volúmenes, 1996-2003.

- Les complots nocturnes. Paris, Futuropolis, 2005.

Deville, R. Lobas. Madrid, Sins Entido, col. Sin nosotras, 2007. Traducción de Lorenzo F. Díaz.

—L'heure du loup. Paris, L'Apocalype, 2013.

Durand, G. Les Structures anthropologiques de l'imaginaire. Paris, Dunod, 1990 [1963].

Fayolle, M. La tendresse des pierres. Paris, Magnani Éditions, 2013.

Ferlut, N. Lettres d'Agathe. Paris, Delcourt, 2008.

Gallardo, V. y Von Gheluwe, M. Pendant que le loup n'y est pas. Génève, les éditions Atrabile, col. Bile Blanche, 2016.

Goblet, D. Faire semblant c'est mentir. Paris, L'Association, 2007.

- Les hommes-loup. Fremok, 2010.

Groensteen, Th. «Le rêve dans la bande dessinée», en Neuvièmeart 2.0. Septiembre 2013. Disponible en http://neuviemeart.citebd.org/spip.php?article616

- Nocturnes. Le rêve dans la bande dessinée. Paris, Citadelles \& Mazenod, 2013.

Lambé, E. Le fils du roi. Fremok, 2012.

Martin, S. La montagne de sucre. Paris, l'Association, 2012.

Mao, C. «L'artiste de bande dessinée et son miroir: l'autoportrait détourné», en Comicalités. Disponible en http://comicalites.revues.org/1702

-La bande dessinée autobiographique francophone (1982-2013): transgression, bybridation, lyrisme. [Tesis doctoral]. Paris IV-Sorbonne, Dirigida por Jacques Dürrenmatt. Defendida el 26 de junio de 2014. 
Miller, A. y Pratt, M. «Transgressive Bodies in the work of Julie Doucet, Fabrice Néaud and Jean-Christophe Menu: Towards a Theory of the AutobioBD'» en Belphégor, vol. 04 n. 1 pp. 15-34, noviembre de 2004. Disponible en http://epress.lib.uts.edu.au/ research/handle/10453/3320

Montellier, Ch. Un deuil blanc. Paris, Futuropolis, 1987.

Peeters, F. Pilules bleues. Génève, Les éditions Atrabile, col. Flegme, 2001.

Quidonoz, J.M. Les rêves qui tournent une page. Rêves d'intégration à contenu paradoxal régressif. Paris, PUF, 2001.

SAmson, J. «Le rêve: un embrayeur pictural», en Neuvièmeart 2.0, n. ${ }^{\circ}$ 11, octubre de 2004, pp. 78-81. Disponible en: http://neuviemeart.citebd.org/spip.php?article228

Satrapi, M. Persépolis. Paris, L'Association, 4 vol., 2000-2003.

Schwartz, B., Le Rêrveur captif. Paris, L’Apocalypse, 2012.

Turgeon, D. «Crise de l'autobiographie», en Du9, l'autre bande dessinée, septiembre de 2010. Disponible en http://www.du9.org/dossier/crise-de-1-autobiographie/

Vanoli, V. L'cil de la nuit. Paris, L'Association, 2012.

Viart, D. «Filiations littéraires», en BAetens, J.y Viart, D. Ecritures contemporaines, vol. 2. États du roman contemporain. Caen, Lettres Modernes Minard, 2000. 